$$
\text { CONF-971147-- }
$$

INVESTIGATION OF EPITAXIAL SILICON LAYERS AS A MATERIAL FOR RADIATION HARDENED SILICON DETECTORS*

\section{Z. Li}

Brookhaven National Laboratory

Upton, NY 11973-5000
RECEIVED

DEC 181997

OSTI

V. Eremin, I. Ilyashenko, A. Ivanov, and E. Verbitskaya Ioffe Physico-Technical Institute, Russian Academy of Sciences

194021 St. Petersburg, Russia

November, 1997

MASTER

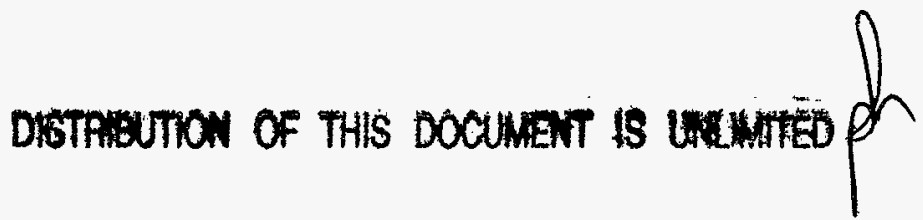

"This work was supported in part by the U. S. Department of Energy: Contract No. DEAC02076CH00016. 


\section{DISCLAIMER}

This report was prepared as an account of work sponsored by an agency of the United States Government. Neither the United States Government nor any agency thereof, nor any of their employees, makes any warranty, express or implied, or assumes any legal liability or responsibility for the accuracy, completeness, or usefulness of any information, apparatus, product, or process disclosed, or represents that its use would not infringe privately owned rights. Reference herein to any specific commercial product, process, or service by trade name, trademark, manufacturer, or otherwise does not necessarily constitute or imply its endorsement, recommendation, or favoring by the United States Government or any agency thereof. The views and opinions of authors expressed herein do not necessarily state or reflect those of the United States Government or any agency thereof. 


\section{DISCLAMERR}

Portions of this docoment may be illegible in electronic image prodnets. Imoges are produced from the best arailable original docoment 


\title{
Investigation of Epitaxial Silicon Layers as a Material for Radiation Hardened Silicon Detectors*+
}

\author{
Z. Li \\ Brookhaven National Laboratory, \\ Upton, New York 11973, USA \\ V. Eremin, I. Ilyashenko, A. Ivanov, and E. Verbitskaya \\ Ioffe Physico-Technical Institute, Russian Academy of Sciences, \\ 194021 St-Petersburg, Russia
}

\begin{abstract}
Epitaxial grown thick layers $(>100 \mu \mathrm{m})$ of high resistivity silicon (Epi-Si) have been investigated as a possible candidate of radiation hardened material for detectors for high-energy physics. As grown Epi-Si layers contain high concentration (up to $2 \cdot 10^{12} \mathrm{~cm}^{-3}$ ) of deep levels compared with that in standard high resistivity bulk Si. After irradiation of test diodes by protons $\left(E_{p}=24 \mathrm{GeV}\right)$ with a fluence of $1.5 \cdot 10^{11} \mathrm{~cm}^{-2}$, no additional radiation induced deep traps have been detected. A reasonable explanation is that there is a sink of primary radiation induced defects (interstitial and vacancies), possibly by as-grown defects, in epitaxial layers. The "sinking" process, however, becomes non-effective at high radiation fluences $\left(10^{14} \mathrm{~cm}^{-2}\right)$ due to saturation of epitaxial defects by high concentration of radiation induced ones. As a result, at neutron fluence of $1 \cdot 10^{14} \mathrm{~cm}^{-2}$ the deep level spectrum corresponds to well-known spectrum of radiation induced defects in high resistivity bulk $\mathrm{Si}$. The net effective concentration in the space charge region equals to $3 \cdot 10^{12} \mathrm{~cm}^{-3}$ after 3 months of room temperature storage and reveals similar annealing behavior for epitaxial as compared to bulk silicon.
\end{abstract}

\section{INTRODUCTION}

One of the attempts to reduce the effect of reverse annealing and to increase reliability of various semiconductor detectors in colliders is to use epitaxial silicon (Epi-Si) as a starting material for detector manufacturing. As the thickness of epitaxial layers $d_{e p}$ is limited by technological aspects of layer growth and can not be comparable with that of bulk silicon, the detectors are elaborated as strip coordinate detectors. The other aspect of epitaxial layer application is the decrease of the bias that is necessary for detector full depletion due to their smaller thickness.

The goal of this study is to investigate silicon detectors made of thick epitaxial Si layers as candidates for radiation hardened detectors. In the study the detectors are

\footnotetext{
*This investigation was done as a part of work established and supported in part by ROSE (RD48, CERN) collaboration.

+This research was supported in part by the U.S. Department of Energy: Contract No. DE-AC02-76CH00016
}

compared with the detectors from bulk silicon irradiated at similar proton or neutron flunkies.

\section{EXPERIMENTAL DETECTORS AND MEASUREMENT TECHNIQUE}

Epitaxial layers of $\mathbf{n}$ and $\mathbf{p}$-type were grown with a resistivity $\rho$ of a few $\mathrm{k} \Omega \cdot \mathrm{cm}$ by ITME, or with a resistivity of $500 \Omega \cdot \mathrm{cm}$ by MACOM, USA, on wafers from low resistivity $(1 \Omega \cdot \mathrm{cm}$ ) CZ Si (Fig.1) with a thickness of $550-600 \mu \mathrm{m}$. The thickness for n-type layer was 100 or $150 \mu \mathrm{m}$, and for p-type layer was 150 or $200 \mu \mathrm{m}$. The detectors used in the study are listed in the Table I. For investigation of microscopic defects in as-grown epitaxial layers and at low irradiation fluence, detectors were manufactured as beveled etched Shottky diodes with metal contacts (Fig. 2). The two planar detectors from ntype Epi Si (C142-C-A33 and C142-C-A34) were studied after high irradiation fluence. Additionally, irradiated detectors from bulk n-type silicon with $\rho$ of $2 \mathrm{k} \Omega \cdot \mathrm{cm}$ produced by Polovodice, Czech Republic, were used in the investigation of radiation hardness as reference detectors.

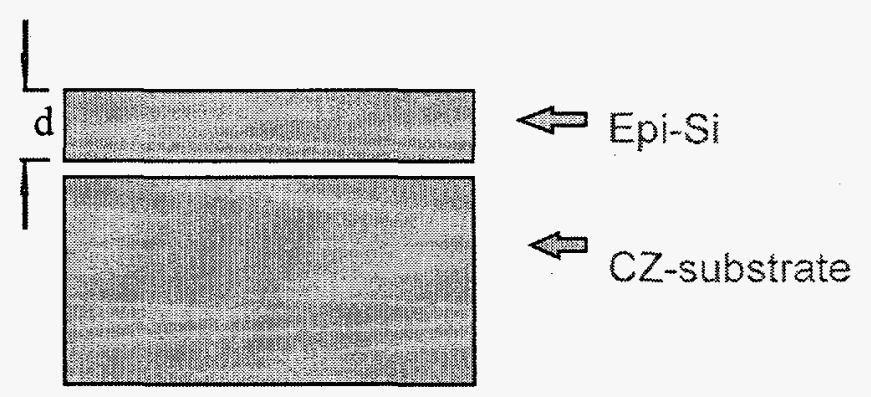

Figure 1 Schematic of Epi-Si layer grown on a CZ-Si substrate

The measurement technique applied in the study are listed the following:

- Current -Voltage measurements (C-V)

- Transient Current Technique (TCT);

- Capacitance Deep Level Transient Spectroscopy (C-DLTS)

in the range of $\mathrm{T}=77$ to $300 \mathrm{~K}$;

- Current Deep Level Transient Spectroscopy (I-DLTS) in the range $T=10$ to $300 \mathrm{~K}$.

C-DLTS measurements were carried out for the nonirradiated detectors or detectors irradiated to low proton 
fluence while I-DLTS technique was used for detectors irradiated at high fluence of neutrons.

Table I Detectors used in the study

\begin{tabular}{|c|c|c|c|c|}
\hline \multicolumn{3}{|c|}{ Detectors under study } & \multicolumn{2}{|c|}{ (Shottky diodes) } \\
\hline \multirow[t]{2}{*}{ Detector \# } & \multicolumn{2}{|r|}{ Epi-layer } & \multirow{2}{*}{$\begin{array}{c}\text { Fluence } \\
{[\mathrm{cm}-2]}\end{array}$} & \multirow[t]{2}{*}{ Radiation } \\
\hline & Type & Thickness [um] & & \\
\hline 121-B-6 & $\mathrm{n}$ & 150 & $\overline{0}$ & no \\
\hline 121-P-B-12 & $p$ & 150 & 0 & no \\
\hline I 31-P-B-12 & $p$ & 200 & 0 & no \\
\hline 121-B-9 & $n$ & 150 & $1.50 \mathrm{E}+11$ & protons \\
\hline 1 21-P-B-15 & $p$ & 150 & $1.50 E+11$ & protons \\
\hline 1 31-P-B-14 & $p$ & 200 & $1.50 \mathrm{E}+11$ & protons \\
\hline C142-C-A3-3 & $n\left(p^{*}\right)$ & 100 & $1.00 E+14$ & neutrons \\
\hline C142-C-A3-4 & $n\left(p^{*}\right)$ & 100 & $1.00 E+14$ & neutrons \\
\hline C142-C-A3-3, & $\begin{array}{l}\text { * - after } \\
\text { Energy } \\
\text { Energy } \\
\text { are plar }\end{array}$ & $\begin{array}{l}\text { fpe inversion und } \\
\text { f protons } E p=24 G \\
\text { f neutrons } E n=1 M \\
\text { ar detectors }\end{array}$ & $\begin{array}{l}\text { r irradiation } \\
\mathrm{eV} \\
\mathrm{eV}\end{array}$ & \\
\hline Reference & dete & ors (bulk Si, & (Ohm-cm) & \\
\hline Detector \# & & Material & Fluence & Radiation \\
\hline Planar det. & Type & Thickness, [um] & & \\
\hline P88-S-A-3-11 & $n$ & 277 & $1.50 \mathrm{E}+11$ & protons \\
\hline P81-C-A3-17 & $p^{*}$ & 300 & $1.00 E+14$ & neutrons \\
\hline
\end{tabular}

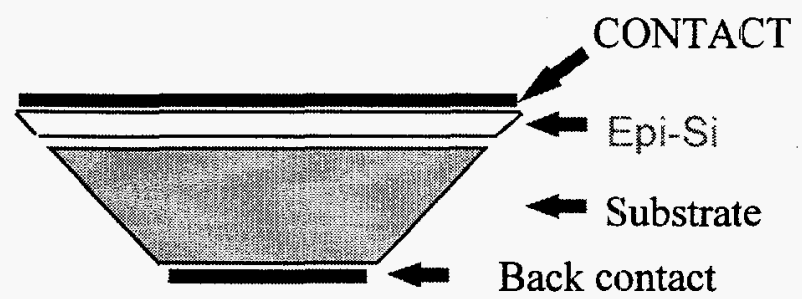

Figure 2 Schematic of a Shottky diode made of Epi-Si.

\section{EXPERIMENTAL RESULTS}

I-V characteristics of non-irradiated detectors from $n$ and p-type epi silicon are shown in Fig. 3. The difference in the current is mainly due to the thickness of the detectors.

The spectrum of deep levels in as-grown epitaxial $n$ type $\mathrm{Si}$ is presented in Fig. 4. Three deep levels act as electron traps with a maximum concentration of $1.5 \cdot 10^{11} \mathrm{~cm}^{-3}$ for the trap E3 (Table II). Deep levels E1 and E3 are similar to thermal induced defects which were occasionally detected in bulk Si after thermal oxidation at $\mathrm{T}>1000^{\circ} \mathrm{C}$. Spectra of deep levels in p-type epi Si (Fig. 5) involve four hole traps (traps of majority carriers) $\mathrm{H} 1$ to $\mathrm{H} 4$ and an electron trap E11. The hole trap $\mathrm{H} 2$ shows the maximum concentration of $-3 \cdot 10^{12} \mathrm{~cm}^{-3}$ which increases superlinear with epitaxial layer thickness, and is an effective trapping center for both electrons and holes.

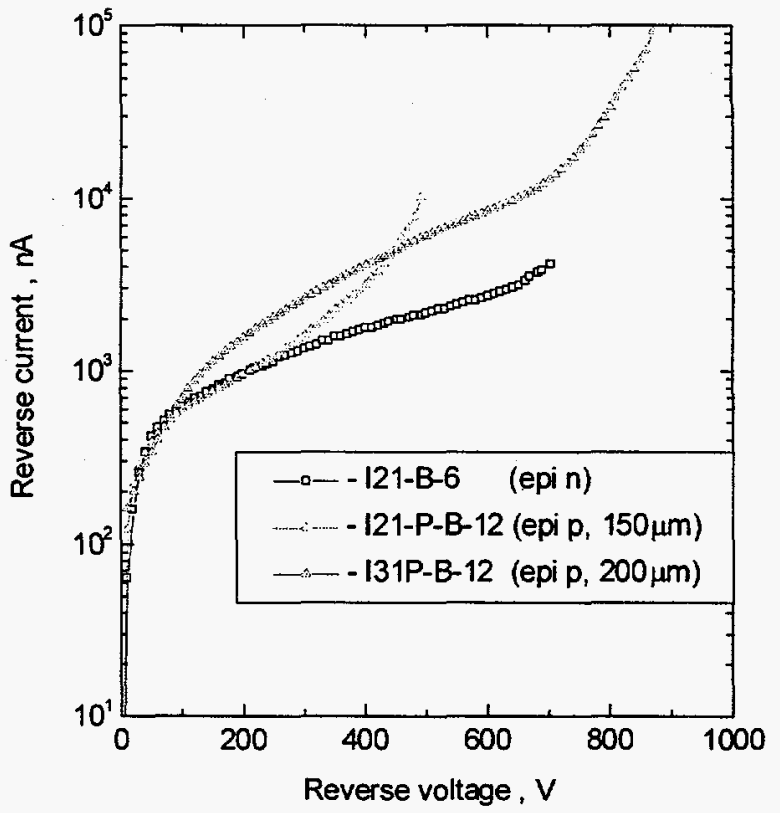

Figure 3 I-V characteristics for non-irradiated Epi-Si detectos

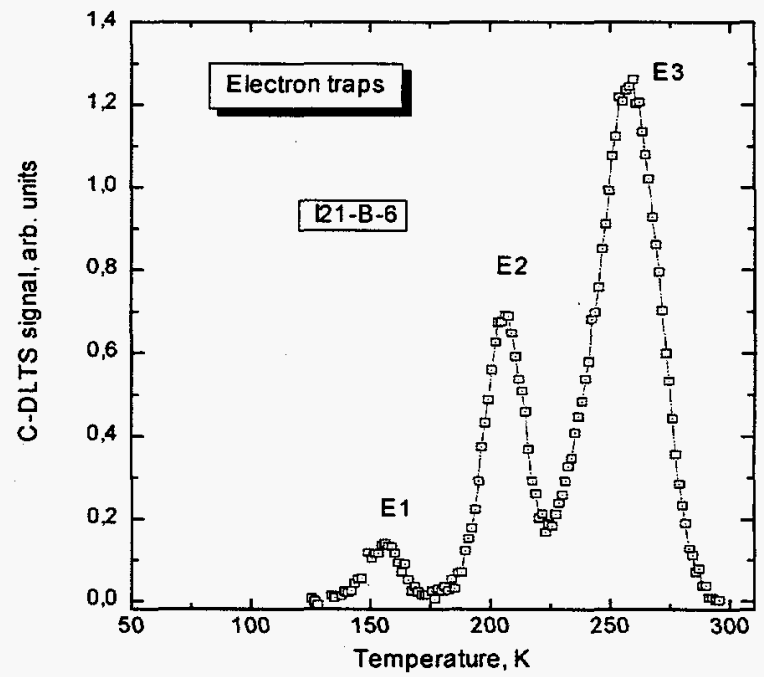

Figure 4 C-DLTS spectrum for an as-grown Epi-Si detector (electron traps

In Fig. 6 C-DLTS spectrum for n-type epi $\mathrm{Si}$ irradiated at low proton fluence $\left(1.5 \cdot 10^{11} \mathrm{~cm}^{-2}\right)$ is compared with a spectrum for non-irradiated epi $\mathrm{Si}$ detector and a spectrum for bulk $\mathrm{Si}$ detector irradiated at the same $\mathrm{F}_{\mathrm{p}}$. It can be seen that only deep levels already existed in as-grown epi layer are detected in the irradiated detector, and no deep levels are induced by irradiation. At the same time for irradiated bulk Si detector, typical radiation induced defects with deep levels E1, E2, E3 listed in Table II (presumably the A-center, divacancies $\mathrm{VV}^{-}$, and $\mathrm{VV}^{-}+\mathrm{E}$-center, respectively) are detected in the concentration range of $\sim 10^{11} \mathrm{~cm}^{-3}$. A 
reasonable explanation of this effect can be the assumption that epitaxial defects act as sinks for radiation induced primary defects (interstitials and vacancies). As for hole traps, only the deep level $\mathrm{H} 2$ is the same for both epi and bulk irradiated n-type Si. Thus, in the range of 77 to $300 \mathrm{~K}$ the main deep levels in the detectors from epitaxial n-type $\mathrm{Si}$ irradiated at low proton fluence are the defects from as-grown epitaxial layers.

Table II Parameters of deep levels in as-grown, non-irradiated EpiSi detectos

\begin{tabular}{|c|c|c|c|c|c|}
\hline \multicolumn{2}{|r|}{ epy-layer } & \multicolumn{4}{|c|}{ Deep level parameters } \\
\hline type & thickness, [um] & Table & {$[\mathrm{E},[\mathrm{eV}]$} & $\mathrm{sig},[\mathrm{cm} 2]$ & $\mathrm{N},[\mathrm{cm}-3]$ \\
\hline $\bar{n}$ & 150 & E1 & EC-0.29 & $3.20 E-16$ & $2.40 E+10$ \\
\hline & & E2 & $E c-0.33$ & $1.00 \mathrm{E}-17$ & $9.10 E+10$ \\
\hline & & E3 & Ec-0.52 & $9.50 \mathrm{E}-16$ & $1.50 E+11$ \\
\hline $\bar{p}$ & 150 & म1 & $E v+0.18$ & $5.30 E-15$ & $4.20 E+10$ \\
\hline & & $\mathrm{H} 2$ & $E v+0.26$ & $1.00 \mathrm{E}-16$ & $2.10 E+12$ \\
\hline & & H3 & $E v+0.2$ & 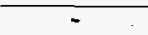 & $1.10 E+11$ \\
\hline & & E11 & Ec-0.27 & $3.60 E-16$ & $6.90 E+11$ \\
\hline $\bar{p}$ & 200 & H1 & $E v+0.18$ & $5.30 \mathrm{E}-15$ & $2.10 E+10$ \\
\hline & & $\mathrm{H} 2$ & $E v+0.26$ & $1.00 \mathrm{E}-16$ & $2.90 E+12$ \\
\hline & & H3 & $E v+0.2$ & - & $1.40 E+11$ \\
\hline
\end{tabular}

In Fig. 7 I-DLTS spectra of the detectors from epi and bulk n-Si irradiated at high neutron fluence of $1 \cdot 10^{14}$ $\mathrm{cm}^{-2}$, measured after 3.5 months of RTA (room temperature anneal), are compared. The spectra are similar, and the main difference is observed in the dominant peak in the range of $T$ $>200 \mathrm{~K}$ (DL \#\# 10,11). This peak is usually attributed to composition of the DLTS signals from single charged divacancies $\mathrm{VV}^{-}$and vacancy related complexes $\mathrm{V}_{\mathrm{n}}-\mathrm{O}$. Parameters of deep levels for epi Si detector are listed in the Table IV. Note that an activation energy of deep level DL11 $\mathrm{E}_{\mathrm{a}}=0.47 \mathrm{eV}$ which has the maximum amplitude is close to that of hole trap $E_{\mathrm{V}}+0.5$ eVwhich was detected by TCT in neutron irradiated silicon detectors from bulk Si. This hole trap contributes to the changes of the net effective concentration of ionized charges $\left(\mathrm{N}_{\mathrm{eff}}\right)$ in the space charge region.

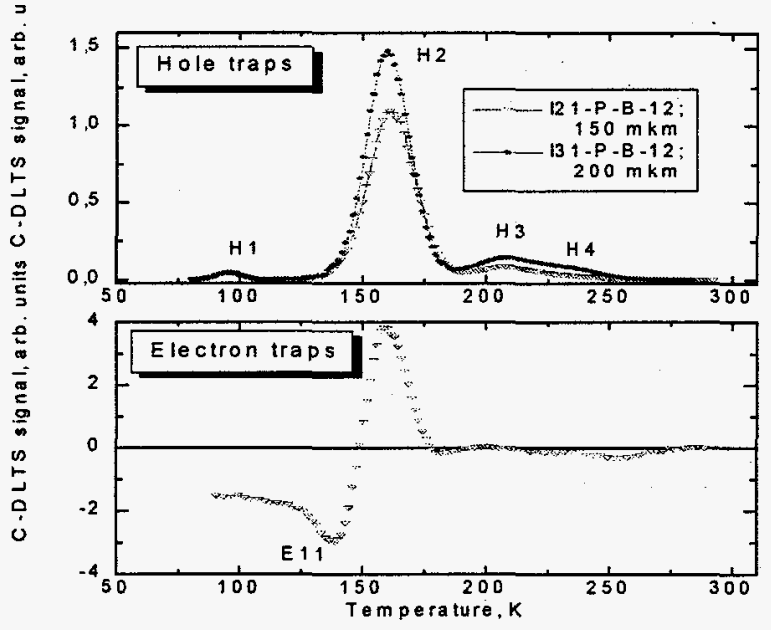

Fig. 5 C-DLTS spectra for an as-grown Epi-Si detector
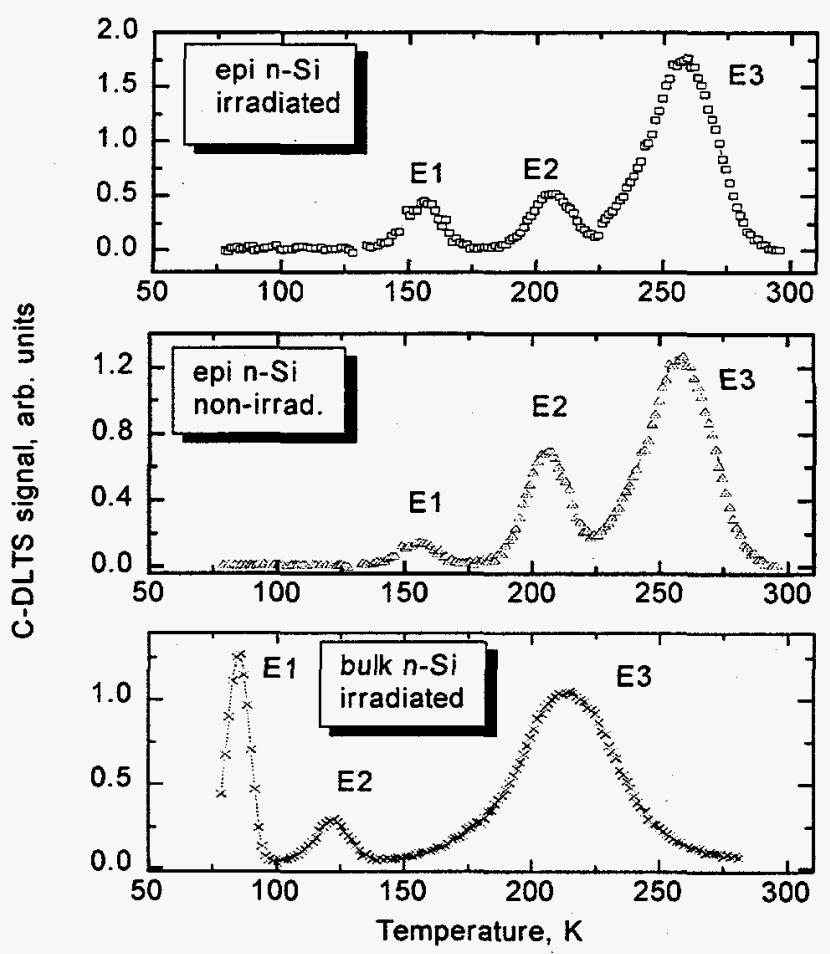

Figure 6 C-DLTS spectrum of lowly irradiated Epi-Si detector as compared to those of a non-irradiated Epi-Si detector and an irradiated bulk detector

Successive steps of elevated temperature annealing (ETA) at $\mathrm{T}=80^{\circ} \mathrm{C}$ were applied to stimulate the $\mathrm{N}_{\text {eff }}$ changes. TCT measurements of charge collection efficiency versus reverse voltage (Fig. 8) showed significant increase of $V_{F D}$ for Epi-Si detectors after 1 to 2 hours of ETA followed by a saturation. In Fig. 9 the data on $V_{F D}$ for two epitaxial detectors are compared with those for bulk silicon irradiated at the same neutron fluence. It can be easily seen that there is a significant difference between the absolute values of $V_{F D}$ for epitaxial and bulk detectors, whereas the values normalized to those after the similar period of RTA differ insignificantly. Estimation of $\mathrm{N}_{\text {eff }}$ after 3 months of RTA followed by 4 hours of ETA gives the value of $\sim 3 \cdot 10^{12} \mathrm{~cm}^{-3}$ for both detectors.

Table III Parameters of deep levels in irradiated Epi-Si detectors and bulk detectos

\begin{tabular}{|c|c|c|c|c|c|}
\hline \multicolumn{2}{|r|}{ epy-layer } & \multicolumn{4}{|c|}{ Deep level parameters } \\
\hline type & thickness, [um] & lable & $E,[e V]$ & sig, [cm2] & $\mathrm{N},[\mathrm{cm}-3]$ \\
\hline \multirow[t]{5}{*}{$\overline{\mathrm{n}}$} & 150 & ET & $E C-0.29$ & $3.20 \mathrm{E}-16$ & $2.00 \mathrm{E}+10$ \\
\hline & & E2 & EC & 17 & $2.00 E+10$ \\
\hline & & E3 & EC- & 9.5 & $5.60 E+10$ \\
\hline & & H1 & $E v+0.34$ & -13 & $1.10 E+11$ \\
\hline & & $\mathrm{H} 2$ & $E v+0.32$ & 1.90E-16 & $7.60 E+10$ \\
\hline \multirow[t]{4}{*}{$n$} & \multirow{4}{*}{$\begin{array}{c}\text { Reference } \\
\text { detector, } \\
\text { bulk Si }\end{array}$} & E1 & EC-0.16 & $9.50 \mathrm{E}-15$ & $1.50 \mathrm{E}+11$ \\
\hline & & E2 & EC-0.24 & $2.50 \mathrm{E}-15$ & $4.00 E+10$ \\
\hline & & E3 & Ec-0.35 & 1.70E-17 & $1.20 \mathrm{E}+11$ \\
\hline & & $\mathrm{H} 2$ & $E v+0.32$ & $2.20 \mathrm{E}-16$ & $1.60 E+1$ \\
\hline
\end{tabular}

The net increase in $\mathrm{N}_{\text {eff }}$ during anneal are about the same for Epi-Si and bulk silicon detectors, indicating similar reverse annealing behavior. The total concentration of $\mathrm{N}_{\text {eff }}$ is lower than bulk value (which is in the order of 6 to $8 \times 10^{12} \mathrm{~cm}^{-3}$ ). 
This is probably due to the fact that the initial resistivity of Epi-Si detectors are about five times lower than that of standard bulk detectors. Hence, the difference in the full depletion voltages arises mainly from the various thickness of the detectors from bulk and epitaxial silicon and initial resistivity.

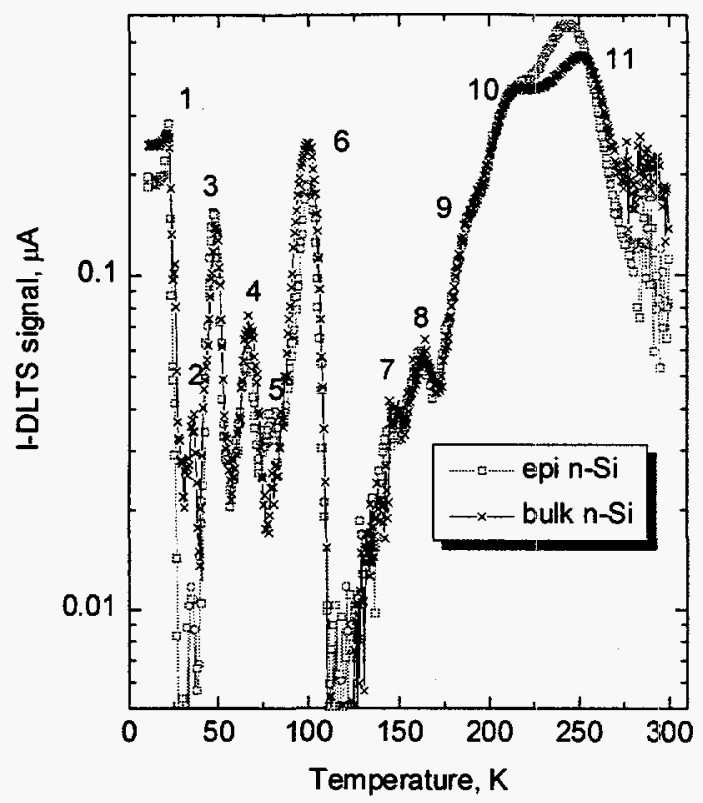

Figure 7 I-DLTS spectra of highly irradiated Epi-Si and bulk Si detectors

Table IV Deep levels in neutron irradiated detectors from epitaxial silicon. Detector \# C142-C-A3-3, $\Phi_{\mathrm{n}}=1.03 \cdot 10^{14} \mathrm{~cm}^{-2}$; RTA, 3.3 months

\begin{tabular}{|c|c|c|c|c|c|c|c|c|}
\hline & 1 & 2 & 3 & 4 & 6 & 9 & 10 & 11 \\
\hline $\begin{array}{c}\mathrm{E}_{\mathrm{a}} \\
\mathrm{eV}\end{array}$ & 0.026 & 0.062 & 0.081 & 0.135 & 0.17 & 0.37 & 0.42 & 0.47 \\
\hline $\begin{array}{c}\sigma \\
10^{-14} \\
\mathrm{~cm}^{-2}\end{array}$ & 0.12 & 0.12 & 8.1 & $?$ & 2.5 & 21.0 & 16.0 & 6.0 \\
\hline
\end{tabular}

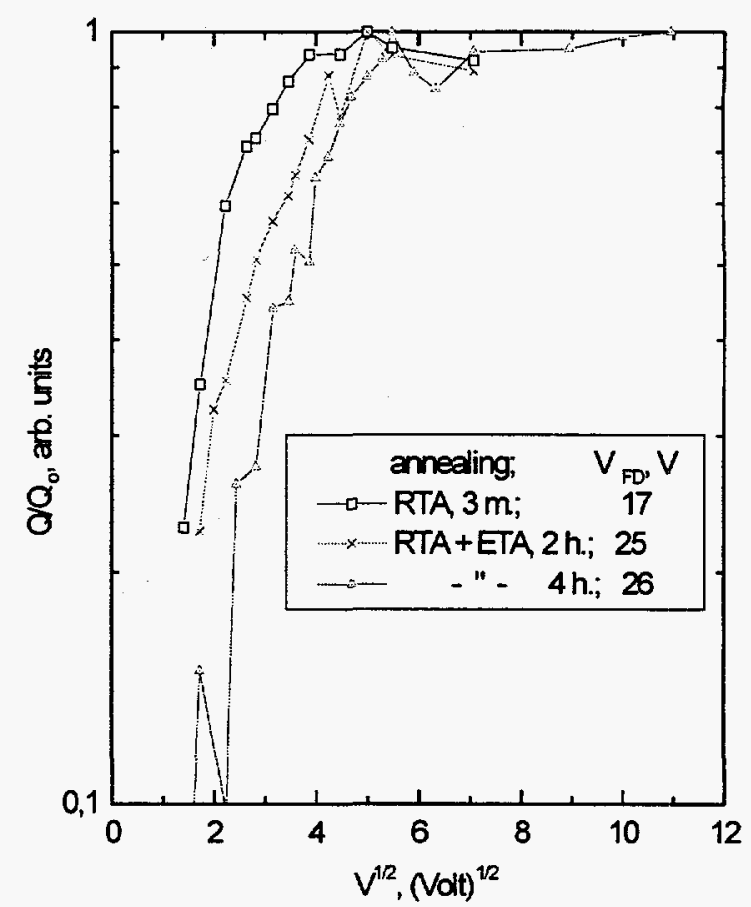

Figure 8 Charge collection efficiencies of various Epi-Si detectors

\section{SUMMARY}

1. Thick $(>100 \mu \mathrm{m})$ epitaxial high resistivity Si layers contain significant concentration (up to $10^{12} \mathrm{~cm}^{-3}$ ) of defects with deep levels compared with that in a standard high resistivity bulk Si.

2. Concentration of epitaxial defects increases superlinear with a thickness of as-grown layer.

3. Epitaxial defects act as sinks for radiation induced primary defects that is evinced by significantly low concentration of radiation induced defects in epitaxial base detectors at low fluences compared with that in control detector produced from bulk Si.

4. At high radiation fluence $\left(10^{14} \mathrm{~cm}^{-2}\right)$ epitaxial defects are saturated by radiation defects, and a standard spectrum of radiation induced defects is detected. The net effective concentration in the space charge region equals to $3 \cdot 10^{12} \mathrm{~cm}^{-3}$ after 3 months of room temperature storage and a following ETA, and reveals similar annealing behavior for epitaxial silicon as compared to bulk silicon. The total concentration of $\mathrm{N}_{\text {eff }}$ is lower than bulk value (which is in the order of 6 to 8 $x 10^{12} \mathrm{~cm}^{-3}$ ). This is probably due to the fact that the initial resistivity of Epi-Si detectors are about five times lower than that of standard bulk detectors.

5. The results show some advantages of epitaxial based material for radiation harden detectors in the low radiation fluence range. More experiments are needed to investigate the main regularities of the effect observed and its development to the problem of radiation hardness of Si detectors. 


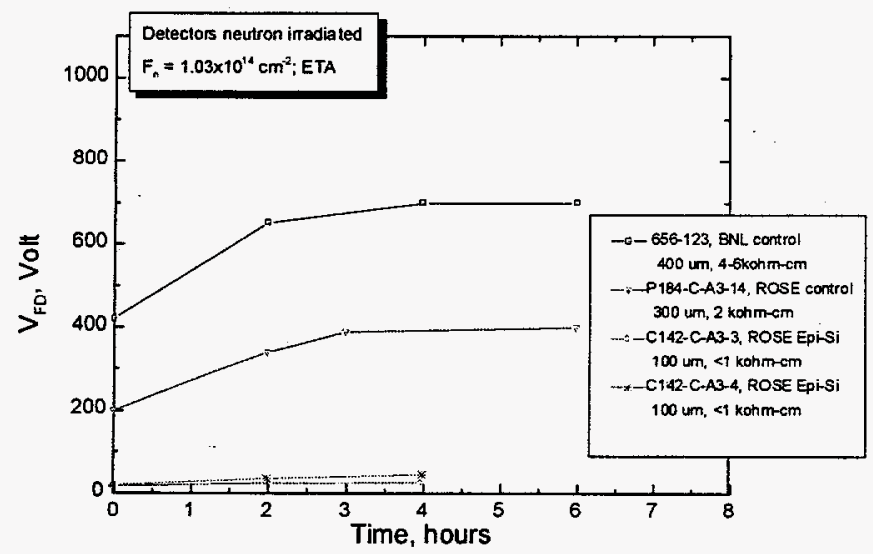

a) Full depletion voltages vs. ETA temperature for various detectors

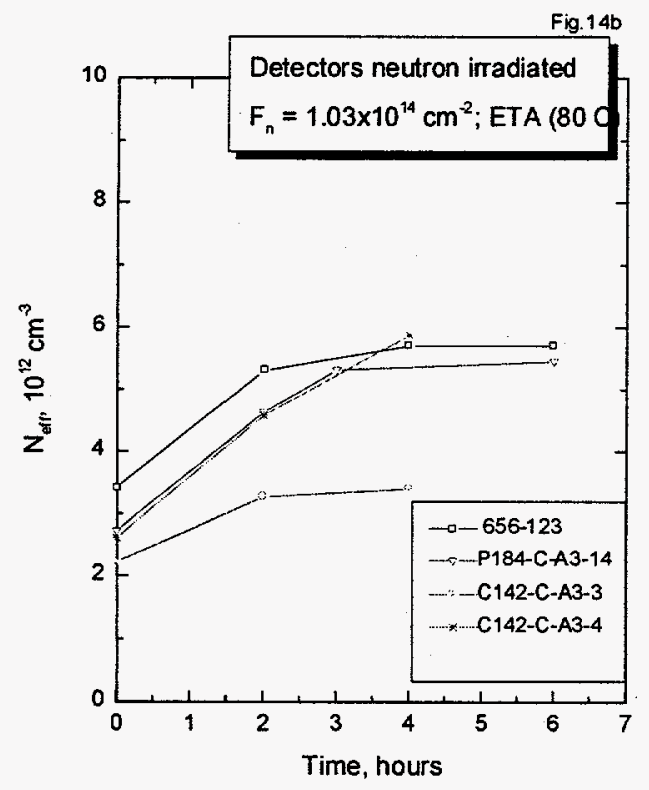

b) $\mathrm{N}_{\text {eff }}$ vs. ETA temperature for various detectors

Figure 9 Reverse annealing behavior for Epi-Si detectors and control detectors 